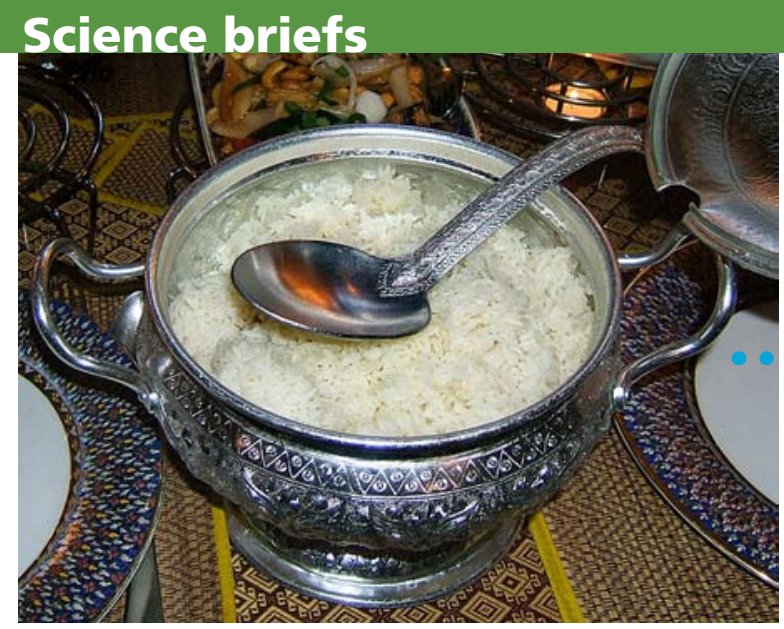

"Low-carbon diet" research looks at total energy usage of foods

Is an organic tomato grown in Mexico better for the environment than a conventional one grown 150 miles away from your Bay Area home? Is it more sustainable to drive to a big-box store and buy lots of groceries to keep in the freezer, or to purchase ready-made meals or cook individual ingredients at home? These types of questions are at the heart of a UC Agricultural Sustainability Institute (ASI) project that is examining the food system's role in climate change.

"Changes in consumer food choices, as well as in our vast food-production system, could contribute substantially to meeting goals for reducing greenhouse gases," ASI director Thomas Tomich says. "Individual foods vary tremendously in their carbon footprints."

The low-carbon diet project uses life-cycle assessment methodology to tally the energy used to produce particular foods, then does computer modeling to estimate greenhouse-gas emissions. Researchers identify and collect data on farming practices, pest control, irrigation, harvesting, processing, transportation, refrigeration, storage and even cooking. "We're looking for all the inputs, from farm to fork," says Gail Feenstra, ASI food systems analyst.

The project has collected data on processing tomatoes, dairy and rice, and Sonja Brodt and Alissa Kendall of UC Davis are currently crunching numbers to find the "break-even" point for the energy usage of rice. A new effort in conjunction with Cornell University, funded by the Kellogg Foundation, will examine the carbon footprints of local foods in California and elsewhere in the United States. ASI is also launching the California Nitrogen Assessment, funded by the Packard Foundation, to further quantify the scope of the state's greenhouse-gas emissions.

An estimated $15 \%$ of U.S. energy usage and greenhouse-gas emissions is related to the food system. The major contributors are livestock-related
UC researchers are estimating the "farm to fork" energy usage for rice - including cooking - as part of the Agricultural Sustainability Institute's low-carbon diet project.

methane and nitrous oxide emissions (see page 79); synthetic nitrogen fertilizers (see pages 84, 91); air freight; heated greenhouse production; post-retail consumer transport and food storage; and food waste at multiple points along the supply system.

"We are developing information so that major food suppliers, food service professionals and retailers, as well as consumers, can figure out where to focus to make the biggest impact on climate change," Feenstra says. - Janet Byron

\section{Climate-change modeling finds many crop yields are likely to decline}

Climate change would likely cause the yields of several major California crops to decline significantly by 2050, while others would not change. Scientists at Lawrence Livermore National Laboratory (LLNL), UC Merced and others recently modeled the effect of climate change for six of California's most valuable perennial crops: wine grapes, almonds, table grapes, oranges, walnuts and avocados (Agricultural and Forest Meteorology 141 [2-4]: 208-18).

"In California, 20 to 30 years is the productive lifespan for most of these plants," says David Lobell, who was agricultural ecologist at LLNL when he led the study. "If we can get a picture of how the climate will change during this interval, we can evaluate what that means in terms of projected crop yields." In addition, keeping the time frame relatively short limits modeling uncertainty.

The projections showed variable results. Winegrape yields, for instance, would change little over the next century, but the other crops exhibited moderate-to-substantial declines. The amount of uncertainty was considerable, but the overall trend was toward decreased yields.

"More than $95 \%$ of the simulations for almonds, table grapes, walnuts and avocados showed a negative response to warming by midcentury," Lobell says. "The current climate is either at or above the optimum temperatures for the crops we studied, and all climate models project at least some warming during this period."

Lobell is now senior research scholar at Stanford University. He and his colleagues have recently expanded their study to more crops in California; it will be released in coming months on the California Energy Commission Climate Action Team Web site. - Editors and Ann Parker
For more information UC Agricultural Sustainability Institute http://asi.ucdavis.edu/ research/energy_food system.htm 